\title{
Atributos determinantes da baixa utilização de bibliotecas:estudo em uma instituição de ensino pública federal
}

\section{Andreia Cristina Damasceno}

\begin{abstract}
Graduada em Biblioteconomia pelo Centro Universitário de Formiga.Especialista em Informática em Educação pela Universidade Federal de Lavras. Mestre em Administração pela Universidade FUMECBibliotecária/documentalista do Instituto Federal de Educação, Ciência e Tecnologia de Minas Gerais - Campus Bambuí
\end{abstract}

José Marcos Carvalho de Mesquita

Economista. Mestre e Doutor em Administração. Professor da Universidade Fumec

Este estudo tem como objetivo analisar o comportamento dos usuários de uma biblioteca de uma instituição de ensino pública federal. Para tanto, utilizou-se como instrumento de pesquisa um questionário fechado, que foi aplicado a 291 usuários reais e potenciais da biblioteca do IFMG - Campus Bambuí. Os dados coletados foram tratados estatisticamente, utilizando os softwares Excel e SPSS $17.0 \mathrm{com}$ a aplicação das análises descritiva, fatorial e discriminante. O referencial teórico foi fundamentado na revisão de literatura sobre marketing de serviços em organizações sem fins lucrativos, entre elas a biblioteca; a qualidade dos serviços oferecidos nas unidades de informação; o comportamento dos utentes de bibliotecas; a infraestrutura administrativa e técnica; e a utilização das bibliotecas. Após a análise dos dados obtidos na pesquisa, identificaram-se os fatores relacionados à utilização da biblioteca, que são: infraestrutura/acervo, acesso/divulgação, incentivo à leitura e hábito de leitura. Destes, o fator acesso/divulgação é o que possui maior relação com a baixa utilização dos serviços de uma biblioteca, seguido, em menor escala, do fator incentivo à leitura. Constatou-se, também, que, entre os entrevistados, $58 \%$ utilizam os serviços da biblioteca com elevada frequência e $40 \%$ com baixa frequência ou não utilizam. 

of libraries:study in a federal public educational institution

\begin{abstract}
This study aims to analyze the library users' behavior of a federal public educational institution. For this purpose, we used a questionnaire applied to 291 actual and potential users of the library of IFMG - Campus Bambuí. The collected data were treated statistically using Excel and SPSS 17.0 with the application of descriptive, factor and discriminant analysis. The theoretical framework was based services marketing in nonprofit organizations, including the library, the service quality offered in information units, the library users' behavior, the administrative and technical infrastructure, the use of libraries. After analyzing the data obtained in the research, the factors related to the use of the library are: infrastructure / collection / disclosure, encourage reading and reading habits. Among them, the factor access / disclosure is the one which has stronger relation with the low use of library services; followed to a lesser extent, the factor of encouraging the reading. It was also found that among the questioned people, 58\% use library services with high frequency and 40\%, with low frequency or do not use.
\end{abstract}

Keywords: Library users; Library; Service marketing

Recebido em 04.03.2013 Aceito em 10.06.2013.

\title{
1 Introdução
}

Nas últimas duas décadas, têm ocorrido grandes transformações na sociedade, fruto do crescimento informacional, do avanço tecnológico, da facilidade de acesso aos diversos suportes informacionais, entre outros. Essas mudanças geram uma sociedade cada vez mais exigente. Nesse cenário, a biblioteca, como uma prestadora de serviços para a comunidade acadêmica, é um setor que deve se adaptar às constantes mudanças, sem deixar de lado seu fim de auxiliar a geração de conhecimento, dando suporte às atividades de ensino, pesquisa e 
extensão (SILVA, 2008). Zamberlan (2010, p. 90) corrobora, ao dissertar que as bibliotecas possuem a missão de:

[...] dar suporte para as atividades de ensino, pesquisa e extensão desenvolvidas pelo corpo docente e discente, além de promover a interação entre a instituição e a comunidade através da disponibilidade de espaço e material para busca da socialização do conhecimento e resgate a cultura da região onde está inserida.

A biblioteca apresenta, também, como finalidade social, a preservação da produção intelectual em qualquer esfera, acrescentado a isso o fornecimento de informações às atividades das pessoas, seja profissional, pessoal ou de qualquer outro interesse, além de agregar valores aos seus produtos, por meio de uma atitude proativa, prevendo-se às alterações do ambiente externo e pressupondo prováveis demandas (SILVA, 1999/2000). Contudo, este setor se tornou peça chave nas instituições de ensino. $\mathrm{E}$, dentre seus diversos objetivos, oferecer serviços com qualidade é um dos principais, pois a prestação dos mesmos é um fator que se tornou primordial na sociedade atual.

Todavia, parte-se do pressuposto de que esses setores, apesar de possuírem grande acervo de periódicos, livros, materiais áudio-visuais e software de última geração para consultá-los, muitas vezes não recebem uma grande demanda pelos usuários.

Deste modo, a aplicação de ferramentas do marketing de serviço nas bibliotecas poderia resolver o problema da baixa procura pelos materiais informacionais e uso inadequado das instalações. Visto que, para desenvolver produtos e serviços que atendam seu público alvo, o bibliotecário deve se basear em diálogos com os usuários que identifiquem as verdadeiras necessidades, expectativas e interesses informacionais para, a partir dos resultados, adotar estratégias de marketing com compromisso com a qualidade, profissionalismo e ética (AMARAL, 1999/2000).

Portanto, diante do questionamento dessa barreira entre biblioteca/usuário, a qual dificulta ao usuário o acesso a valiosas informações para sua formação acadêmica e/ou cultura em geral, esta pesquisa teve como objetivo geral analisar o comportamento dos utentes de uma biblioteca de uma instituição de ensino pública federal.

Este artigo está estruturado, além desta introdução, em outras quatro seções. Na segunda, é feita uma breve revisão da literatura sobre marketing de serviços e sua aplicação nas bibliotecas, a qualidade na prestação de serviços, satisfação e comportamento do consumidor, além da infraestrutura e os desafios que as bibliotecas têm enfrentado com as mudanças advindas do avanço tecnológico. Em seguida, são apresentados os procedimentos metodológicos. Os resultados de cada fase da análise são apresentados e discutidos na quarta seção. Por fim, a seção de conclusões reúne as principais implicações da pesquisa, discute limitações e sugestões para estudos futuros. 


\section{Referencial teórico}

Os serviços fazem parte do cotidiano de todas as pessoas, sejam os de transportes, restaurantes, hospedagens, elétricos, de telefonia, dos correios, manutenções diversas, cabeleireiros, dentistas, médicos, lazer, enfim, o tempo todo o homem utiliza serviços que atendam suas necessidades de sobrevivência. A complexidade e diversidade desses serviços impulsionaram o crescimento econômico durante o último século, o qual estimulou o desenvolvimento da indústria de serviços, já que, com o aumento da prosperidade, as pessoas, empresas e instituições preferem comprar serviços a gastar o tempo realizando atividades por conta própria. Quanto maior a qualidade e a diferenciação, mais importância o serviço terá (BATESON; HOFFMAN, 2001).

Gronroos (2003, p. 84) define serviço como "uma série de processos cuja produção e consumo não podem ser separados, e nos quais, muitas vezes, o cliente participa do processo de produção". Para Bateson; Hoffman (2001), serviço é algo que não é físico, que não se pode consumir ou levar consigo. Ainda caracterizam os serviços como intangíveis, por não serem vistos ou tocados; inseparáveis por produção e consumo, ou seja, primeiramente são vendidos, depois produzidos e consumidos concomitantemente; heterogêneos, devido ao potencial de variabilidade no desempenho de serviços; e perecíveis por não poderem ser estocados.

Uma das funções básicas do marketing "é identificar as necessidades dos consumidores de modo a projetar um serviço cujo desempenho atenda a estas necessidades" (GIANESI; CORRÊA, 2007). O marketing de serviços vem justamente para atender estas necessidades. Lima Filho (2001, p. 1) o define como "as atividades operacionais destinadas a investigar, obter e servir à demanda por assistência profissional. Nestas atividades, incluem-se as tarefas de desenvolvimento e promoção de serviços pessoais e comunitários".

Nas organizações sem fins lucrativos, o marketing possui muitas semelhanças ao que é aplicado em organizações com fins lucrativos. Essa semelhança se deve, em parte, ao fato das primeiras possuírem orientação para os clientes, entendendo, assim, as necessidades do público-alvo. Nas palavras de Shiraishi; Campomar (2007, p. 4), "o marketing ganha importância como uma função administrativa nas organizações sem fins lucrativos quando estas se relacionam com seu ambiente por meio do entendimento das características e estruturas do comportamento dos grupos-alvo".

Assim como uma organização sem fim lucrativo, o marketing em unidades de informação é definido por Ottoni (1995, p. 1) como "uma filosofia de gestão administrativa na qual todos os esforços convergem em promover, com a máxima eficiência possível, a satisfação de quem precisa e de quem utiliza produtos e serviços de informação. É 0 ato de intercâmbio de bens e satisfação de necessidades". 
Com o marketing, as bibliotecas alcançarão novos lugares na indústria da informação e, assim, haverá uma mudança em relação ao aumento da frequência e ao seu uso por parte dos usuários (OLIVEIRA, 1985). Silva (1999/2000, p. 10) complementa que o desenvolvimento do marketing "é de grande utilidade para os serviços informacionais em seus esforços para atrair novos usuários e para prevenir que os usuários não abandonem o serviço e para estimular o aumento do número de consultas".

Há, ainda, uma crescente preocupação, por parte dos profissionais da informação, em oferecer serviços com qualidade e agilidade. Como os serviços de informação são "as organizações sociais responsáveis pelo armazenamento, tratamento e disseminação de informações" (SILVA, 2008, p. 3-4), o seu planejamento deve-se orientar aos consumidores, especialmente "na relação qualidade do produto/serviço versus percepção do consumidor e tal satisfação [...] o conteúdo e a qualidade de um serviço de informação dependem da interação entre o prestador de serviços e seu público-alvo". É necessário compreender e transpor para o lado do consumidor, tomando uma atitude de simpatia e empatia na oferta da informação (AMARAL, 1999/2000).

Este processo de comunicação é de grande importância na qualidade da prestação de serviços. O usuário deve saber se comunicar, ser claro a respeito da informação que necessita, fornecendo, assim, insumos necessários para que ocorra a qualidade neste processo (GRONROOS, 1993). Por outro lado, o bibliotecário, tendo a função de entender e proporcionar a informação de forma adequada ao usuário, de modo a saciar as suas necessidades de busca, deve estar sempre apto para auxiliar o usuário, compreendendo o que ele realmente procura, mesmo em situações em que ele não saiba ou não consiga expressar o que deseja (BEHR; MORO; ESTABEL, 2010).

Assim, a qualidade na prestação de serviços será alcançada "quando cada indivíduo na biblioteca compreender e adotar a filosofia da melhoria constante e quando todos os processos/atividades estiverem sob controle estatístico" (BELLUZZO; MACEDO, 1993, p. 128).

Contudo, a prestação de serviços deve acontecer de forma planejada, a fim de atender as necessidades e expectativas do consumidor e, também, atingir os objetivos organizacionais. "Compreender o comportamento, as preferências e os fatores determinantes da escolha do consumidor por diferentes meios de prestação do serviço passa a ser fundamental para o sucesso de qualquer empresa de serviços" (BRASIL, 2002, p. 3).

\subsection{Comportamento dos usuários de biblioteca}

O comportamento dos usuários de bibliotecas vem se transformando rapidamente (SILVA, 2008), diante da facilidade de acesso às diversas bases de dados via $W e b$, que, na maioria das vezes, preferem ficar no conforto de suas residências para fazer suas pesquisas. Embora as 
bibliotecas adotem as novas tecnologicas, não é apenas automatizando seus serviços que irão atender satisfatoriamente aos usuários. É necessário que os profissionais da informação procurem identificar suas necessidades, desejos e expectativas, as quais nem sempre são as mesmas (AMARAL, 1999/2000).

De acordo com Baptista, Cunha (2007), há mais de 40 anos, realizase estudos sobre os usuários de bibliotecas.

Na década de 1960, a preocupação era quanto à frequência de uso dos materiais. Era abordada de forma puramente quantitativa, somente após um tempo que se passou a analisar e avaliar o comportamento do usuário perante determinada necessidade.

Já nos anos 70, as pesquisas identificaram como os usuários obtinham e utilizavam a informação, concluindo-se que esta utilização dependia da facilidade de acesso e, nem sempre, a informação utilizada era a melhor.

$\mathrm{Na}$ década de 80 , os estudos de usuários voltaram-se para a automação, o intuito era de planejar serviços ou sistemas de informação que satisfizessem as necessidades dos clientes. No entanto, devido à complexidade de definir o comportamento e as necessidades informacionais dos usuários, os resultados não foram os esperados. Obtiveram-se apenas os aspectos de funcionamento das bibliotecas e não o comportamento e necessidades individuais dos usuários.

A partir do momento em que os estudiosos do comportamento de busca da informação "perceberam que as pesquisas com métodos quantitativos não contribuíam para a identificação das necessidades individuais e para a implementação de sistemas de informação adequados a essas necessidades" (BAPTISTA; CUNHA, 2007, p. 173), eles decidiram passar para a fase qualitativa. Esta fase é marcada pelo emprego de teorias de outras áreas do conhecimento, um exemplo é a abordagem de Taylor, em que se discute a informação de valor agregado, ou seja, o usuário buscava a informação e transformava os dados obtidos em informação útil. Informação esta que ele utilizava para explicar, informar e colaborar quanto à tomada de decisões e ações referente ao seu desenvolvimento pessoal, cultural e profissional (BAPTISTA; CUNHA, 2007).

Portanto, ao criar e utilizar a informação de maneira estratégica, as pessoas podem administrar suas vidas, suas empresas, com intuito de crescimento e capacidade de adaptação, construindo, assim, uma organização do conhecimento (CHOO, 2006). Esta organização é composta por três arenas, que funcionam como processos integrados, alimentando-se e complementando-se reciprocamente, por meio de um olhar holístico tem como resultado o uso da informação (BEHR; MORO; ESTABEL, 2010).

De acordo com Choo (2006), a primeira arena refere-se à criação de significado. Como as empresas vivem em um ambiente dinâmico e de constantes incertezas, elas utilizam a informação para dar sentido às transformações do ambiente externo. Criar significado para os integrantes 
da organização é construir um consenso a respeito do que ela faz e do que ela é. A segunda arena é a que a organização constrói conhecimento, ou seja, por meio do aprendizado ela cria, organiza e processa a informação, transformando-a em um novo conhecimento. Este, por sua vez, possibilita a criação de novos produtos e serviços, desenvolvimento e aperfeiçoamento de capacidades e processos. A terceira arena diz respeito à tomada de decisão, a organização interpreta todas as informações obtidas para, racionalmente e baseada em conhecimentos voltados à finalidade da instituição, tomar a melhor decisão.

Sob o ponto de vista do usuário, Lira et al. (2007) propuseram um modelo de decisão do uso da informação, baseado em quatro estágios que levam os usuários a procurar pela informação, de acordo com suas necessidades e objetivos, para tomarem as decisões. Ressaltando que clientes buscam fontes de informações e instruções de como utilizá-las, no entanto, clientes com as mesmas consultas necessitam de respostas diferentes. Estes estágios são:

a)reconhecimento da necessidade do uso da informação: o cliente percebe a diferença entre o estado desejado e a situação real. Este sentimento de falta de informação deve ser forte o suficiente para levar o cliente a buscar novos conhecimentos, seja por motivos pessoais (internos do indivíduo) ou profissionais (ambientais);

b)busca da informação: neste estágio, os usuários rompem a lacuna existente em seu conhecimento, seja para resolver um problema vivenciado ou atender determinada necessidade pessoal/profissional. Esta busca se dará por meio de dois tipos: interna, quando há uma recuperação na memória permanente dos dados que antecedem 0 estágio de reconhecimento da necessidade de uso da informação; e externa, quando o usuário consegue fontes de referências externas, sejam de colegas, palestras, internet, cursos ou demais fontes;

c)decisão de uso da informação: dentre todas as informações coletadas, o usuário irá selecionar as que melhor atendam suas necessidades, levando em conta fatores como: confiabilidade, quantidade, qualidade e facilidade na obtenção da informação; e

d)avaliação pós-uso da informação: após a utilização das informações coletadas, o usuário analisa o grau de influência das mesmas quanto a sua satisfação pela informação. Satisfeita, há grande probabilidade de compartilhamento e propagação da informação, transformando-a em conhecimento, caso contrário, o usuário poderá ter aversão à informação e ao seu meio de veiculação. 
Desta forma, a procura por informação torna-se um ciclo em que novas necessidades surgirão aos usuários e a informação só será considerada útil assim que o usuário gerar-Ihe significado, pois, uma informação objetiva pode ser interpretada com diferentes significados subjetivos por distintos usuários (CHOO, 2006).

Contudo, as bibliotecas que não forem capazes de oferecer os produtos que divulgam e cujas mensagens não forem objetivas, se tornarão meros depósitos, ultrapassados pela concorrência baseada na experiência de administração e marketing. Apenas as bibliotecas que tiverem uma clara definição de sua finalidade, que sabem, articulam e cumprem seus propósitos, serão reconhecidas como organizações de informação viável (SILVEIRA, 1987).

Há, ainda, uma grande necessidade de diferenciação exigida pelos usuários que solicitam adaptações específicas para o contexto local. As bibliotecas deverão se adaptar, tornando suas estruturas, papéis e funções diversificadas (SILVEIRA, 1987), criando novos serviços "como a orientação aos usuários na utilização de seus recursos, o desenvolvimento de home-pages, o agendamento e o atendimento de novos serviços online, como a comutação, o empréstimo entre bibliotecas, a disseminação da informação e o catálogo" (BUENO; VIDOTTI, 2000, p. 6).

Outro desafio aos gestores é oferecer serviços que unam a capacidade tecnológica juntamente com a interação humana. Esses serviços e tecnologias devem ser simpáticos aos usuários, treinando-os no uso de seus recursos, na identificação e criação de suas próprias opções para, finalmente, perseguir seus diversos objetivos (SILVEIRA, 1987).

A adoção das novas tecnologias de informática, unidas aos suportes informacionais, possibilitará, assim, novos processos de organização, análise, recuperação e disseminação da informação, fundamentados na estrutura de associação de ideias, objetos ou itens. Com o benefício de que as informações disponibilizadas em uma biblioteca possam estar simultaneamente em quantos locais forem necessários, seja via internet e/ou intranet e, também em ambientes informacionais hipertextuais e multisensoriais, nos quais o usuário torna-se um gerenciador ativo no processo de armazenamento e de recuperação das informações interrelacionadas, por meio do multidimensionamento dos pontos de acesso informacionais (BUENO; VIDOTTI, 2000). O profissional que conseguir vencer estes desafios, visualizará "a unidade de informação como um 'negócio', cuja missão é satisfazer as necessidades do usuário, procurando aprimorar a prestação de serviços" (SUGAHARA; FUENTES; OLIVEIRA, 2003, p. 86). Para isso, ele deverá "assumir compromisso em relação às responsabilidades sociais que terá frente às inovações tecnológicas e competitivas que o desafiarão", mantendo-se "ligado às inovações tecnológicas", "atualizado" e "participando de cursos de capacitação" (p. 87).

\subsection{Infraestrutura administrativa e técnica das bibliotecas}


Para que a biblioteca possa exercer sua missão de dar suporte para o ensino, pesquisa e extensão e ser um ambiente agradável e acolhedor, é necessário que, além de oferecer serviços com qualidade, ela possua uma infraestrutura adequada para atender todas as necessidades de seus usuários. Para isso, ela deve ter: "disponibilidade, quantidade, qualidade e atualidade do acervo, espaço adequado ao estudo, horário de atendimento compatível com a organização da vida no campus, etc." (SANTOS; MARQUES, 2002, p. 13).

Conforme critérios de avaliação do MEC, existem alguns indicadores concernentes à infraestrutura das bibliotecas, para que elas possam oferecer boas condições de usabilidade aos seus usuários. São eles:

a)instalações para o acervo, estudos individuais e em grupo: abrange todas as instalações para acomodar o acervo e os ambientes para estudos individuais e em grupo. A biblioteca deve atender adequadamente as condições de dimensão para o número de usuários, acústica, ventilação, iluminação, limpeza e mobiliário (BRASIL, 2006);

b)informatização: é por meio da informatização que o usuário terá acesso às informações que lhe são necessárias para a realização de suas pesquisas (BRASIL, 2006). De acordo com Lubisco (2002), a informatização pode ser dividida em:

1)informatização do acervo: atividade de cadastrar o acervo eletrônicamente por meio de software que integre as funções da biblioteca, permitindo a consulta por, no mínimo, autor, título e assunto, com a indicação do status das obras;

2)informatização do sistema de consulta: originária da informatização do acervo, este indicador abrange não apenas se uma determinada obra está disponível e, sim, informações sobre sua existência, localização e acesso. Também propicia condições de acesso a bases de dados em CD-ROM e online nacionais e estrangeiras, participação em serviços cooperativos e em redes de serviços; e

3)informatização do sistema de empréstimo: concerne ao processo propriamente dito de consulta nas máquinas, tendo em vista à verificação da disponibilidade da obra almejada e a possibilidade de cedê-la ao usuário pelo período prédeterminado;

c)políticas institucionais de aquisição, expansão e atualização do acervo e formas de sua operacionalização: refere-se às políticas para aquisição, conservação e atualização de todo o acervo, de acordo com o Plano de Desenvolvimento Institucional (PDI), com a proposta pedagógica e prioridades para as bibliografias básicas e complementares dos cursos da Instituição (BRASIL, 2006; LUBISCO, 2002); 
d)serviços - condições, abrangência e qualidade: a partir da implementação das políticas institucionais constantes nos documentos oficiais da Instituição, é essencial que haja uma diretriz de ação, acessível ao conhecimento da comunidade interna e externa no que se refere aos seguintes serviços ofertados pela biblioteca:

1)horário de funcionamento compatível com todos os turnos dos cursos, inclusive aos sábados e se a biblioteca apresenta a possiblidade de reserva de livros pela internet;

2)empréstimo entre bibliotecas e empréstimo domiciliar dos itens que compõem o acervo;

3)acesso ao serviço de cópia de documentos internamente na instituição e de documentos técnico-científicos disponíveis nos acervos das principais bibliotecas brasileiras e em serviços de informação internacionais;

4)consulta a bases de dados disponíveis diretamente na instituição, ou via acesso remoto a recursos de outras instituições;

5)orientação aos usuários quanto à normalização de trabalhos acadêmicos, de acordo com as normas da ABNT (BRASIL, 2006);

e)recursos humanos: é indispensável que o quadro de pessoal seja qualificado, responsável, que todos tenham vontade de servir e busquem tornar o mais útil possível o acervo da biblioteca. O responsável deve ter o diploma de bacharel em biblioteconomia e os auxiliares técnicos, no mínimo, já terem cursado o ensino médio. O número de funcionários deve ser compatível com a quatidade de alunos matriculados e a necessidade da instituição (BRASIL, 2006; PRADO, 1992, p. 16).

\subsection{Utilização das bibliotecas}

Perante a grande quantidade de informações disponíveis nos diferentes formatos (livros, periódicos, CD's, DVD's, internet, etc.) e instantaneidade da comunicação, as bibliotecas são instituições que têm sentido o impacto desse avanço. Neste panorama, os gestores enfrentam o desafio de dar sentido a estas informações, ou seja, disponibilizá-las a um público que se torna cada vez mais exigente e atraí-lo às bibliotecas.

No entanto, alguns estudos apontam que estas instituições enfrentam o problema da baixa utilização de seus recursos informacionais, conforme pode-se observar no Quadro 1. 
Quadro 1 - Construtos relacionados à baixa utilização das bibliotecas

\begin{tabular}{ll}
\hline \multicolumn{1}{c}{ Autor } & \multicolumn{1}{c}{ Constructo } \\
\hline \hline Wilson (1977) & - Tempo, esforço e dificuldade de utilizar os documentos \\
Figueiredo (1992) & - Comportamento e atuação dos bibliotecários \\
& - Barreiras e problemas sócio-político-econômico-cultural \\
Silva (1999/2000) & - Desenvolvimento de acervo sem pesquisa de interesse \\
& - Diversidade e facilidade de acesso à informação fora da biblioteca. \\
& - Usuários não conhecem os serviços oferecidos e procuram outras fontes para obter as \\
& informações que necessitam \\
& - Ausência do hábito de leitura \\
& - Inexistência de divulgação dos serviços oferecidos \\
& - Funcionários não são treinados para atender adequadamente \\
Carvalho; Giraldes; Berbel & - Falta de divulgação dos serviços ofertados e demora no atendimento \\
& - Acervo desatualizado, poucos títulos de periódicos específicos e ausência de indexação dos \\
& artigos \\
& - Poucos computadores para pesquisas em bases de dados em Cd'rom; \\
& - Ausência do hábito e de incentivo à leitura \\
& - Usuários não se conscientizam da importância de saber utilizar a biblioteca adequadamente \\
& - Necessidade de um melhor relacionamento biblioteca/usuário \\
& - Extensa carga horária dos alunos, impede que os mesmos tenham um horário exclusivo para \\
& utilizar a biblioteca \\
Cruz et al. (2003) & - Professores não estimulam os alunos a fazerem pesquisas e frequentar a biblioteca \\
\hline
\end{tabular}

Fonte: Elaborado pelos autores, com base em WILSON (1977), FIGUEIREDO (1992),

SILVA (1999/2000), CARVALHO; GIRALDES; BERBEL (2000) e CRUZ et al. (2003).

\section{Metodologia}

A presente pesquisa teve uma abordagem quantitativa. Quanto aos fins, foi de caráter descritivo, com o objetivo de descrever, identificar e obter informações sobre a utilização do acervo e dos serviços de disseminação do conhecimento oferecidos pela Biblioteca do Instituto Federal Minas Gerais (IFMG) - Campus Bambuí, de acordo com os fatores de infraestrutura/acervo, acesso/divulgação, incentivo à leitura e hábito de leitura, os quais foram extraídos de construtos abordados no referencial teórico.

Quanto aos meios, teve como campo de estudo uma instituição de ensino pública federal. A população pesquisada foram os servidores efetivos e contratados, funcionários terceirizados e os alunos matriculados no IFMG - Campus Bambuí, nos cursos de ensino médio, nível técnico, ensino superior - níveis tecnólogo, bacharelado e licenciatura.

Utilizou-se a amostragem não-probabilística por conveniência, a qual "procura obter uma amostra de elementos convenientes. A seleção de unidades amostrais é deixada a cargo do entrevistador" (MALHOTRA, 2006 , p. 326). Para determinar o tamanho da amostra, foi utilizada a regra de dez observações por questão, resultando um total de 291 questionários aplicados, dentre os quais foram validados 280 .

A fim de obter a opinião dos usuários reais e potenciais da biblioteca, utilizou-se para a coleta de dados um questionário fechado, 0 qual foi elaborado a partir de indicadores encontrados na revisão bibliográfica. Utilizou-se no questionário a escala Likert, que é uma escala de avaliação com cinco categorias, muito usada para que os entrevistados apontem um grau de concordância (Concordo Totalmente) ou discordância (Discordo Totalmente) (MALHOTRA, 2006). 
Para realizar a tabulação dos dados, utilizou-se o software Excel e para processar e analisar as respostas foi utilizado o software estatístico SPSS 17.0.

\section{Resultados}

A análise estatística dos dados foi dividida em três etapas: 1) análise descritiva exploratória, para caracterização da amostra; 2) análise fatorial, para descrever a forma de agrupamento das variáveis; e 3) análise discriminante.

\subsection{Descrição da amostra}

Por se tratar de uma pesquisa em uma instituição de ensino, cuja maioria dos cursos oferecidos se concentra na área de ciências agrárias, a maior percentagem de usuários é do sexo masculino (60\%).

Quanto ao 'tipo de usuário', dentre os 280 questionários validados, $80,35 \%$ dos usuários respondentes é da categoria 'acadêmico', seguido de $7,14 \%$ da categoria 'técnico administrativo', de $5,71 \%$ de 'funcionário terceirizado' e 'professor efetivo' e, por último, com 1\%, os 'professores contratados'. Devido ao fato do IFMG - Campus Bambuí, oferecer todas as modalidades de ensino, a faixa etária da categoria 'acadêmico' é muito extensa, abrangendo alunos que vão dos 14 aos 60 anos de idade. Apesar dessa grande diferença, o maior percentual dos respondentes se concentrou na faixa etária de 14-23 anos, totalizando $73 \%$ da amostra.

Pelo fato da pesquisa ter sido realizada em um Instituto Federal, que é uma instituição de ensino pública, procedente de um antigo Centro Federal de Educação Tecnológica (CEFET) e Colégio Agrícola, seus alunos são originários de classes econômicas com baixa renda, entre 1 a 5 salários míninos. Entre estes, 39\% das famílias dos respondentes recebem mensalmente até três salários e $29 \%$ entre três e cinco salários.

Além do indicativo 'renda familiar', outro dado interessante refere-se à escolaridade, pois a maior parte dos pais de todos os usuários respondentes possui apenas o ensino fundamental incompleto. Estes dados demonstram o crescente interesse das pessoas em apurar seu nível de escolarização, visto que, além do tipo de usuário acadêmico, que atualmente cursa o ensino técnico ou superior, a maioria dos demais tipos de usuários possui mestrado completo.

Referente ao hábito de leitura, como acontece com a maioria da população brasileira, a pesquisa apontou que $60 \%$ dos utentes da biblioteca leem em média de 1 a 3 livros anualmente e, dentre os diversos tipos de fontes informacionais existentes, eles buscam informações na internet ou na internet e televisão, para terem conhecimento de notícias regionais, nacionais e internacionais.

Tendo como referência os dados anteriormente expostos, percebese que a biblioteca possui um baixo índice de utilização no que se refere à busca de informações atualizadas, assim, baseado na Questão 6 (Com qual frequência você utiliza os serviços da biblioteca?) do questionário, 
identificou-se o nível de utilização da biblioteca. O resultado foi agrupado nas variáveis alta e baixa utilização. A alta utilização foi identificada a partir das frequências 'diária', 'quinzenal' e 'mensal', totalizando $58 \%$, e a baixa utilização a partir das frequências 'esporádica' e 'nunca vai à biblioteca', com 40\%. A partir deste resultado, serão utilizados os termos alta utilização e baixa utilização para se referir à frequência à biblioteca.

\subsection{Fatores determinantes da utilização das bibliotecas}

Visando identificar os fatores relevantes para a utilização dos serviços da biblioteca, foi estimada uma análise fatorial. Dessa forma, após realizar o ajuste do modelo fatorial, considerando todas as 23 variáveis apresentadas no questionário, observou-se que nove indicadores, apresentaram cargas fatoriais elevadas em mais de um fator, sendo assim, excluídas das novas análises. Após a exclusão dessas variáveis, foi ajustado um novo modelo de análise fatorial com quatro fatores. Nesta análise, uma variável apresentou baixa carga fatorial com todos os fatores, sendo excluída das análises posteriores.

Depois da rotação pelo método Varimax, identificaram-se quatro fatores, responsáveis por $55,81 \%$ da variabilidade dos dados, os quais são constituídos pelas variáveis constantes no Quadro 2.

Quadro 2 - Construtos e Indicadores dos Fatores

\begin{tabular}{|c|c|}
\hline FATOR & INDICADORES \\
\hline $\begin{array}{c}\text { Fator } 1 \text { - } \\
\text { Infraestrutura/Acervo }\end{array}$ & $\begin{array}{l}\text { 14) Na biblioteca há computadores disponíveis para consulta à base de dados do } \\
\text { acervo }\end{array}$ \\
\hline & $\begin{array}{l}\text { 15) Dentre os periódicos disponíveis na biblioteca, há títulos na área que você } \\
\text { possui maior interesse }\end{array}$ \\
\hline & $\begin{array}{l}\text { 17) Sempre que você precisou ir à biblioteca para fazer uma pesquisa ou leitura, } \\
\text { encontrou material bibliográfico com as respostas para esclarecer suas dúvidas } \\
\text { 25) No acervo há uma quantidade suficiente de títulos e exemplares para atender a } \\
\text { todos os usuários }\end{array}$ \\
\hline $\begin{array}{c}\text { Fator } 2 \text { - } \\
\text { Acesso/Divulgação }\end{array}$ & $\begin{array}{l}\text { 24) O horário de funcionamento da biblioteca é condizente com sua disponibilidade } \\
\text { de horários }\end{array}$ \\
\hline & 27) Você conhece todos os serviços que são oferecidos pela biblioteca \\
\hline & 30) Você, sozinho, consegue localizar determinado material na biblioteca \\
\hline $\begin{array}{l}\text { Fator } 3- \\
\text { Incentivo à Leitura }\end{array}$ & $\begin{array}{l}\text { 12) Os professores que você teve no decorrer de sua vida escolar, tinham/tem o } \\
\text { hábito de frequentar a biblioteca }\end{array}$ \\
\hline & $\begin{array}{l}\text { 13) Desde criança você foi incentivado a adquirir o hábito pela leitura } \\
\text { 22) Os professores que você teve no decorrer de sua vida escolar, sempre o } \\
\text { incentivaram a procurar a biblioteca na busca de respostas às suas dúvidas em } \\
\text { relação aos assuntos abordados em sala de aula }\end{array}$ \\
\hline Fator $4-$ & 26) Você tem o hábito de comprar livros e revistas \\
\hline Hábito de Leitura & $\begin{array}{l}\text { 28) Você possui o hábito de "baixar" livros pela internet } \\
\text { 29) Você tem o hábito de ler diariamente }\end{array}$ \\
\hline
\end{tabular}

Fonte: Dados da Pesquisa (2011).

O Teste de Bartlett, com significância de 0,000 e a Medida de Adequação da Amostra (KMO), no valor de 0,717, indicaram ser o conjunto de dados adequado para a análise fatorial.

A confiabilidade dos construtos, medida pelo Alfa de Cronbach, situou-se próxima do limiar inferior de 0,6, sugerido por Hair et al. (2005) e Mesquita (2010), alcançando valores de 0,6575, 0,5984, 0,5898 e 
0,5604, respectivamente. Dada à natureza inédita dos fatores, optou-se pela continuidade do estudo.

Os testes de validade convergente e discriminante foram feitos com base na correlação entre escores fatoriais e escalas múltiplas. Observa-se que há alta correlação entre o escore fatorial e a escala múltipla, correspondentes ao mesmo fator. Já a validade discriminante pode ser comprovada pelas baixas correlações entre escores fatoriais e escalas múltiplas de fatores distintos. Por fim, observa-se a unidimensionalidade dos construtos, pois percebe-se que, em análises realizadas para cada um, um único fator com autovalor maior que 1 foi extraído.

\subsection{Fatores responsáveis pela baixa utilização das bibliotecas}

A fim de identificar os fatores que levam a possível subutilização pelos usuários do setor de biblioteca, foi aplicada a análise discriminante, realizada a partir dos fatores e dos atributos resultantes da análise fatorial. Para tanto, como dito anteriormente, a variável 6 do questionário (Com qual frequência você utiliza os serviços da biblioteca?) foi categorizada em alta utilização e baixa utilização.

Com o Teste de Igualdade das Médias dos Grupos, percebeu-se que existe diferença significativa entre as médias dos grupos somente para o Fator 2 (Acesso/Divulgação) (valor-p<0,05). Logo, pode-se imaginar que o fator 2 seria o melhor para discriminar os grupos em estudo.

Já o teste de Box's M mostrou que não há evidências estatísticas para rejeitar a homogeneidade das matrizes de variância e covariância.

O coeficiente de correlação canônica $(0,289)$, apesar de significativo, revelou baixo poder discriminatório da função discriminante estimada.

Assim, com base nos coeficientes padronizados, a função discriminante (Escore Z) seria:

$$
Z=0,217 \text { (Fator 1) + 0,916(Fator 2) +0,363 (Fator 3) + 0,115 (Fator 4) }
$$

Baseado nos coeficientes da matriz de estrutura, observa-se que o fator 2 é o mais importante para separar os grupos, ficando em segundo plano o fator 3 (Incentivo à Leitura). Os outros dois fatores (Infraestrutura/Acervo e Hábito de Leitura) não se mostraram relevantes.

Por fim, utilizando a função discriminante, há 119 classificações corretas das observações pertencentes ao grupo Alta Utilização e 38 classificações corretas das observações pertencentes ao grupo Baixa Utilização; sendo assim, 65,4\% dos casos seriam classificados nos grupos originais pela Análise Discriminante.

Devido ao reduzido poder discriminatório da função estimada, com base nos escores fatoriais, optou-se pela estimação de uma função discriminante baseada nos próprios indicadores.

O Teste de Igualdade das Médias dos Grupos mostrou que existe diferença significativa entre as médias dos grupos para os atributos 14, 15, 24, 27, 29 e 30 (QUADRO 2) (valor-p<0,05). Pode-se, então, concluir 
que, possivelmente, essas variáveis permitirão discriminar os grupos em estudo.

Também neste caso, o Teste $M$ de Box indicou equivalência de variâncias e o coeficiente de correlação canônica foi um pouco mais alto, 0.371 , ainda distante de um elevado poder discriminatório.

Entretanto, o mais importante na análise é avaliar quais são os indicadores capazes de separar os tipos de usuários, os resultados mostrados na matriz de estrutura servem bem a esse propósito. Pela ordem, os indicadores são: 29, 14, 30, 15, 27 e 24 (Quadro 2).

Interessante que os indicadores 30, 27 e 24 compõem o fator 2 (Acesso/Divulgação), os indicadores 14 e 15 o fator 1 (Infraestrutura/Acervo) e o 29 está no fator 4 (Hábito de Leitura). No caso dos indicadores 30, 27 e 24, as médias concedidas pelos altos usuários foram sempre superiores. Elas referem-se ao acesso e divulgação, o que permite imaginar que os usuários frequentes estejam já cientes, mas, talvez, falte comunicação aos usuários menos frequentes.

Com relação aos indicadores 14 e 15, relativos à infraestrutura e acervo, os usuários mais frequentes apresentaram médias mais altas, o que permitiria deduzir que problemas na seleção do acervo estejam ocorrendo e poderiam estar relacionados às necessidades de alguns usuários.

Quanto ao indicador 29, relaciona-se com hábito de leitura, mostrando um problema já identificado no fator 3. Neste caso, os baixos usuários concederam notas mais baixas. Tal questão remete mais a um problema cultural, já que é notória a pequena dedicação do brasileiro aos hábitos de leitura, fato comprovado pelas respostas à questão 5 (Quantos livros você lê por ano?).

$\mathrm{Na}$ função discriminante, há 117 classificações corretas das observações pertencentes ao grupo Alta Utilização e 53 classificações corretas das observações pertencentes ao grupo Baixa Utilização; sendo assim, 70,8\% dos casos seriam classificados nos grupos originais pela Análise Discriminante.

A partir dos resultados dos fatores e dos atributos da análise discriminante, constata-se que um confirma o outro, em que, a alta utilização teve classificação de 119 e 117 e a baixa utilização, 38 e 53 respectivamente.

\section{Considerações finais}

Destarte, para analisar como se comportam os usuários da biblioteca do IFMG - Campus Bambuí, objetivo geral deste estudo, primeiramente buscou-se verificar sua frequência de utilização. A partir dos resultados obtidos nas análises descritiva, fatorial e discriminante, identificou-se que $58 \%$ dos entrevistados utilizam os serviços oferecidos com elevada frequência e $40 \%$ com baixa frequência ou não utilizam. Apesar da alta utilização ter sido predominante e tendo como referência a importância que este espaço representa para a formação dos cidadãos, 
além da atuação da pesquisadora como profissional da ciência da informação, pode-se considerar esta percentagem (58\%) baixa. Ponderando que a pesquisa foi realizada em uma Instituição de Ensino Pública Federal, parte-se do pressuposto de que os usuários (reais ou potenciais), apesar da facilidade de acesso às informações pelos diversos meios eletrônicos, devessem ter mais interesse ou serem mais estimulados em buscar novos conhecimentos neste setor.

Assim, a fim de identificar os fatores relevantes para a utilização dos serviços da biblioteca e fundamentado nos autores citados no referencial teórico, constatou-se que os atributos proeminentes para a utilização dos serviços da biblioteca podem ser agrupados em quatro fatores, assim denominados:

a)infraestrutura/acervo: refere-se à quantidade, qualidade, disponibilidade e atualidade de todo o acervo; ambiente (ventilação, iluminação, acústica, entre outros) propício ao estudo e pesquisa; e equipamentos que possibilitem o acesso às informações;

b)acesso/divulgação: considerou-se neste fator o horário de funcionamento da biblioteca, a facilidade de obter acesso aos diversos materiais que compõem o acervo e se há divulgação de todos os serviços que são oferecidos pela biblioteca aos usuários;

c)incentivo à leitura: levou-se em consideração se desde criança $o$ utente foi incentivado a adquirir 0 hábito pela leitura; e

d)hábito de leitura: este fator compreendeu o hábito que o usuário possui de ler e se o mesmo tem o costume de comprar ou baixar livros e revistas pela internet.

A partir dos quatro fatores identificados na análise fatorial, verificouse que as causas da possível subutilização dos serviços da biblioteca relacionam-se ao fator 2 (Acesso/Divulgação) e, em menor escala, ao fator 3 (Incentivo à Leitura). Tais resultados foram confirmados pela análise discriminante.

Este resultado vem de encontro à literatura citada no referencial teórico, em que atributos como atendimento, divulgação, infraestrutura, acesso, entre outros, são imprescindíveis para o bom êxito dos setores de prestação de serviços, entre estes, a biblioteca.

Além disso, confirmam-se os achados de Carvalho; Giraldes; Berbel (2000) e Silva (1999/2000), que enumeraram todos os construtos incluídos na análise como causadores da baixa utilização de bibliotecas, tais como: falta de divulgação dos serviços ofertados aos usuários por parte da biblioteca, acervo desatualizado, ausência do hábito e incentivo pela leitura, diversidade e facilidade de acesso à informação fora da biblioteca, entre outros. 
Entretanto, os resultados de Cruz et al. (2003) não foram corroborados, já que relacionam-se a hábitos de pesquisa via meios eletrônicos, os quais não foram computados nesta pesquisa, uma vez que o reduzido hábito de leitura foi o responsável pela baixa utilização.

Já os achados de Figueiredo (1992) foram indiretamente confirmados, na medida em que algumas questões estão associadas à atuação dos bibliotecários. Também os fatores culturais relativos aos hábitos de leitura foram identificados por esse autor.

Em síntese, com a pesquisa foi possível ter uma concreta visão sobre a utilização da biblioteca do IFMG - Campus Bambuí. Conhecer os pontos fortes e fracos em que se devem elaborar estratégias de marketing, baseadas no referencial teórico, para oferecer serviços que atendam aos usuários reais e atraiam os potenciais. Entre os diversos serviços a serem oferecidos, podem-se citar alguns, como:

a)agendamento de visitas orientadas ao setor com os coordenadores de cursos, a fim de divulgar e explicar o funcionamento e os serviços oferecidos pelo setor;

b)organização de exposições e feiras literárias;

c)convite a autores para momentos de bate-papo com usuários;

d)divulgação do setor via e-mail dos usuários, no jornal do Campus, distribuição de folders autoexplicativos, montagem de uma homepage da biblioteca;

e)organização de cursos de atendimento aos funcionários do setor;

f)oportunizar momentos de conversas com os usuários, a fim de conhecer suas necessidades; e

g)criação de uma política de desenvolvimento de coleção, com efetiva participação de todos os tipos de usuários.

Com a criação das estratégias de marketing, será possível que a biblioteca contribua não apenas com a oferta de informação, mas, sim, com a formação de mentes pensantes, que sabem exatamente o que desejam.

Os resultados também contribuem com a literatura biblioteconômica e auxiliam outras instituições e profissionais da ciência da informação no que se refere à utilização das bibliotecas de instituições de ensino. Da mesma forma, contribui com a literatura de marketing de serviços, pois se trata da prestação de um serviço essencial ao desenvolvimento tecnológico e científico de uma nação, além de sua relevância no tocante ao crescimento cultural da comunidade acadêmica.

Cabe, por último, listar algumas limitações da pesquisa. Por se tratar de uma amostra não aleatória, a generalização dos resultados não pode ser feita. Ademais, os entrevistados possuem um perfil sócio 
econômico peculiar, pois se trata de uma escola pública federal, gratuita, cujos alunos são oriundos de famílias com renda média limitada (68\% com até cinco salários mínimos mensais), o que explica as questões relativas ao baixo hábito de leitura.

Assim sendo, pesquisas contemplando um universo maior de estudantes, preferencialmente incluindo alunos da rede privada de ensino, seriam capazes de explicar o comportamento de uma parcela considerável da população acadêmica brasileira, não contemplada na presente pesquisa.

\section{Referências}

AMARAL, S. A. O profissional da informação e as técnicas de marketing. Revista de Biblioteconomia de Brasília, Brasília, v. 23/24, n. 2, p. 173$188,1999 / 2000$, edição esp. Disponível em:

$<$ http://164.41.122.25/portalnesp/ojs-

2.1.1/index.php/RBB/issue/view/62>. Acesso em: 2 ago. 2010.

BAPTISTA, S. G.; CUNHA, M. B. da. Estudo de usuários : uma visão global dos métodos de coleta de dados. Perspectivas em Ciência da Informação, Belo Horizonte, v. 12, n. 2, p. 168-184, maio/ago. 2007. Disponível em: <www.scielo.br/pdf/pci/v12n2/v12n2a11.pdf >. Acesso em: 28 jun. 2011.

BATESON, J. E. G.; HOFFMAN, K. D. Marketing de serviços. 4. ed. Porto Alegre: Bookamn, 2001.

BEHR, A.; MORO, E. L. da S.; ESTABEL, L. B. Uma proposta de atendimento às necessidades de informação dos usuários da biblioteca escolar por meio do benchmarking e do sensemaking. Informação \& Informação, Londrina, v. 15, n. 1, p. 37-54, jan./jun. 2010. Disponível em: <http://www.uel.br/revistas/uel/index.php/informacao/article/viewArticle/4350>. Acesso em: 26 set. 2010.

BELLUZZO, R. C. B.; MACEDO, N. D. de. A gestão da qualidade em serviços de informação : contribuição para uma base teórica. Ciência da Informação, Brasília, v. 22, n. 2, p. 124-132, maio/ago. 1993. Disponível em:

$<$ http://revista.ibict.br/index.php/ciinf/article/viewArticle/1179 $>$. Acesso em: 06 out. 2011.

BRASIL. Ministério da Educação. Avaliação externa de instituições de educação superior : diretrizes e instrumentos. Brasília, DF, fev. 2006. Disponível em:

$<$ http://www.uepg.br/cpa/pdf/Avaliacao Institucional Externa.pdf $>$. Acesso em: 19 out. 2011.

BRASIL, V. S. Sistemas de prestação de serviços : um enfoque no processo de escolha do consumidor. In: ENCONTRO NACIONAL DA ANPAD, 26., 2002, Salvador. Anais... Salvador: ANPAD, set. 2002. 
BUENO, M. C.; VIDOTTI, S. A. B. G.. Ferramentas de busca na internet: pra quê, por quê e como utilizá-las? In: SIMPÓSIO NACIONAL DE BIBLIOTECAS UNIVERSITÁRIAS, 11., 2000, Florianópolis. Anais eletrônicos... Florianópolis : UFSC, 2000. Disponível em: < http://snbu.bvs.br/snbu2000/parallel.html>. Acesso em: 25 jun. 2011.

CARVALHO, E. L. de; GIRALDES, M. J. C.; BERBEL, N. A. N. Uso da Biblioteca Central da Universidade Estadual de Londrina por alunos de pós-graduação em Ciências de Alimentos. In: SIMPÓSIO NACIONAL DE BIBLIOTECAS UNIVERSITÁRIAS DA AMÉRICA LATINA, 11.; SIMPÓSIO DE DIRETORES DE BIBLIOTECAS UNIVERSITÁRIAS DA AMÉRICA LATINA E DO CARIBE, I., 2000, Florianópolis. Anais eletrônicos... Florianópolis : UFSC, 2000. Disponível em: <snbu.bvs.br/snbu2000/docs/pt/doc/t125.doc>. Acesso em: 19 abr. 2011.

CHOO, C. W. A organização do conhecimento: como as organizações usam a informação para criar significado, construir conhecimento e tomar decisões. 2. ed. São Paulo : Senac, 2006.

CRUZ, A. A. A. C. da et al. Impacto dos periódicos eletrônicos em bibliotecas universitárias. Ciência da Informação, Brasília, v. 32, n. 2, p. 47-53, maio/ago. 2003. Disponível em: < http://www.scielo.br/pdf/ci/v32n2/17032.pdf>. Acesso em: 19 abr. 2011.

FIGUEIREDO, N. M. de. A modernidade das cinco leis de Ranganathan. Ciência da Informação, Brasília, v. 21, n. 3, p. 186-191, set./dez. 1992. Disponível em:

$<$ http://revista.ibict.br/index.php/ciinf/article/viewArticle/1277>. Acesso em: 19 abr. 2011.

GIANESI, I. G. N.; CORRÊA, H. L. Administração estratégica de serviços: operações para a satisfação do cliente. São Paulo: Atlas, 2007.

GRONROOS, C. Marketing: gerenciamento e serviços - a competição por serviços na hora da verdade. Rio de Janeiro: Campus, 1993.

GRONROOS, C. Marketing: gerenciamento e serviços. 2. ed. Rio de Janeiro : Elsevier, 2003.

HAIR Jr., J. F. et al. Análise multivariada de dados. 5. ed. Porto Alegre: Bookman, 2005.

LIMA FILHO, A. de O. Marketing de serviços, 2001. Disponível em: $<$ http://www.portaldomarketing.com.br/Artigos/Marketing\%20de\%20servicos.htm $>$.

Acesso em: 10 ago. 2010.

LIRA, W. S. et al. Processo de decisão do uso da informação. Perspectivas em Ciência da Informação, Belo Horizonte, v. 12, n. 2, p. 64-80, maio/ago. 2007. Disponível em: shttp://portaldeperiodicos.eci.ufmg.br/index.php/pci/article/viewFile/283/83>. Acesso em: 29 ago. 2011. 
LUBISCO, N. M. L. A biblioteca universitária e o processo de avaliação do MEC: alguns elementos para o planejamento da sua gestão. In: SIMPÓSIO NACIONAL DE BIBLIOTECAS UNIVERSITÁRIAS, 12., 2002, Recife. Anais eletrônicos... Recife : UFPE, 2002. Disponível em: < http://www.sibi.ufrj.br/snbu2002/oralpdf/117.a.pdf >. Acesso em: 19 out. 2011.

MALHOTRA, N. K. Pesquisa de marketing: uma orientação aplicada. 4. ed. Porto Alegre : Bookman, 2006.

MESQUITA, J. M. C. de. Estatística multivariada aplicada à administração: guia prático para utilização do SPSS. Curitiba: CRV, 2010.

OLIVEIRA, S. M. de. Marketing e sua aplicação em bibliotecas: uma abordagem preliminar. Ciência da Informação, Brasília, v. 14, n. 2, jul./dez. $1985 . \quad$ Disponível em: <revista.ibict.br/index.php/ciinf/article/download/1439/1057>. Acesso em: 26 jun. 2011.

OTTONI, H. M. Bases do marketing para unidades de informação. Ciência da Informação, Brasília, v. 25, n. 2, p. 1-11, 1995. Disponível em: $<$ http://revista.ibict.br/index.php/ciinf/article/viewArticle/433>. Acesso em: 28 mar. 2011.

PRADO, H. de A. Organização e administração de bibliotecas. 2. ed. rev. São Paulo: T. A. Queiroz, 1992.

SANTOS, A. H. dos; MARQUES, R. M. R. A infraestrutura da biblioteca central da universidade Estadual de Maringá em avaliação: uma contribuição necessária. In: SIMPÓSIO NACIONAL DE BIBLIOTECAS UNIVERSITÁRIAS, 12., 2002, Recife. Anais eletrônicos... Recife : UFPE, 2002. Disponível em: <http://www.sibi.ufrj.br/snbu2002/oralpdf/4.a.pdf>. Acesso em: 18 out. 2011.

SHIRAISHI, G. de F.; CAMPOMAR, M. C. Atividades de marketing em organizações sem fins lucrativos: um estudo exploratório em entidades ambientalistas. In: SEMINÁRIOS DE ADMINISTRAÇÃO FEA-USP, 10., 2007, São Paulo. São Paulo : USP, 2007. Disponível em: $<$ http://www.ead.fea.usp.br/semead/10semead/sistema/resultado/an resumo.asp?c od trabalho=573 > . Acesso em: 04 abr. 2011.

SILVA, A. F. G. da. Marketing em unidades de informação: revisão crítica. Revista de Biblioteconomia de Brasília, Brasília, v. 23/24, n. 1, p. 5-24, 1999/2000, edição Esp. Disponível em:

$<$ http://164.41.122.25/portalnesp/ojs-

2.1.1/index.php/RBB/search/advancedResults >. Acesso em: 9 ago. 2010.

SILVA, M. C. de S. e. Marketing em bibliotecas universitárias. In: SEMINÁRIO NACIONAL DE BIBLIOTECAS UNIVESITÁRIAS, 15., 2008, São Paulo: Anais eletrônicos... [S.l. : s.n.], 2008. Disponível em: <http://www.sbu.unicamp.br/snbu2008/anais/site/pdfs/2640.pdf. >. Acesso em: 11 ago. 2010. 
SILVEIRA, A. (Org.). Marketing em bibliotecas e serviços de informação. Brasília: IBICT, 1987.

SUGAHARA, C. R.; FUENTES, L. F.; OLIVEIRA, S. M. de. Marketing: uma ferramenta fundamental para 0 profissional da informação. Transinformação, Campinas, v. 15, n. 1, p. 83-88, jan./abr. 2003. Disponível em: <http://revistas.puccampinas.edu.br/transinfo/viewissue.php?id=2\#Artigos $>$. Acesso em: 11 ago. 2010.

WILSON, P. Public knowledge, private ignorance: toward a library and information policy. Westport: Greenwood Press, 1977.

ZAMBERLAN, C. O. Análise de satisfação nas Instituições de Ensino Superior: um estudo na Biblioteca Acadêmica da Universidade Estadual de Mato Grosso do Sul - unidade de Ponta Porã. Gestão Contemporânea, Porto alegre, v. 7, n. 7, p. 85-100, jan./jun. 2010. <Disponível em: seer2.fapa.com.br/index.php/arquivo/article/view/54/25>. Acesso em: 29 jun. 2011. 